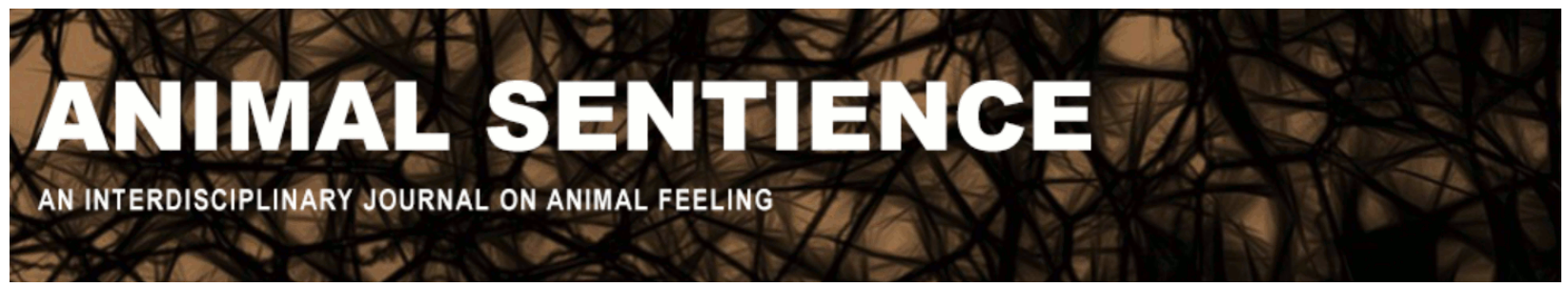

Paez, Eze (2020) Preserving nature for the benefit of all sentient individuals. Animal Sentience 27(18)

DOI: $10.51291 / 2377-7478.1551$

Date of submission: 2020-01-31

Date of acceptance: 2020-02-07

(c)

This article has appeared in the journal Animal

Sentience, a peer-reviewed journal on animal

cognition and feeling. It has been made open access,

free for all, by WellBeing International and deposited

in the WBI Studies Repository. For more information,

please contact

wbisr-info@wellbeingintl.org.

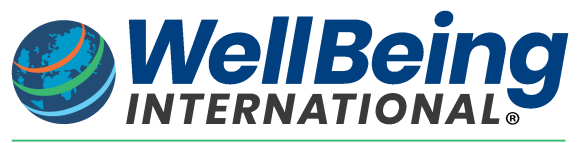

SOLUTIONS FOR PEOPLE, ANIMALS AND ENVIRONMENT 


\title{
Preserving nature for the benefit of all sentient individuals
}

Commentary on Treves et al. on Just Preservation

\author{
Eze Paez \\ Centre for Ethics Politics and Society \\ University of Minho
}

\begin{abstract}
I agree with Treves et al.'s proposal for a preservation ethics based on the principle that nonhuman well-being is a matter of justice and compassion. In this commentary, I advance two objections. First, only sentient beings, rather than all life, belong in the moral community. Second, given that nature is probably harmful overall for sentient individuals, preserving it for the benefit of future human and nonhuman generations requires us to modify it as far as practicable.
\end{abstract}

\begin{abstract}
Eze Paez conducts research on what we owe to nonhuman animals from a variety of moral perspectives, including act- and ruleconsequentialism, as well as Kantian ethics. He is especially interested in the wrongness of killing animals and our reasons for alleviating wild animal suffering. Website
\end{abstract}

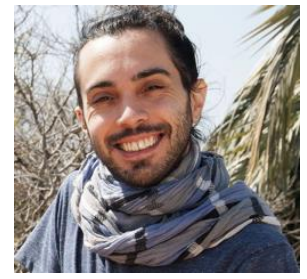

The target article by Treves et al. (2019) is commendable for raising the key question of "the ethics and justice of preserving nature" within a robust anti-speciesist framework. The authors also understand preservation, and rightly so in my view, as saving nature for posterity, rather than as guaranteeing an 'untouched' and 'permanent' natural status quo. Thus, they set themselves the task of identifying the axiological and normative principles that should govern our preservation efforts. However, any such account should include, first, a criterion for identifying the future entities for whose benefit nature is to be saved; and second, a criterion for identifying what is beneficial and what is detrimental to such entities. In what follows, I shall endeavor to explain the problems I see in Treves et al.'s proposals regarding these issues. I will also suggest how I think they should be addressed.

Nature is to be preserved for all sentient beings. The first problem is that the authors do not distinguish between the object of our preservation efforts - what is to be preserved - and the subjects whom that preservation should benefit. On the one hand, they seem to embrace ethical individualism as opposed to the holism espoused by commentators Washington (2019) and Bergstrom (2019). Thus, Treves et al. concede that individuals are 'the actual selves (not objects) with claims'. It is to these selves that we directly owe duties of justice. If their 'collectives (populations, species, habitats, ecosystems)' matter, it is only derivatively. That is, they do not matter in themselves, but simply because they are composed of morally considerable individuals.

Yet, on the other hand, Treves et al. endorse too broad a concept of who merits moral consideration. They of course include all human and nonhuman animals within the moral community; but they also suggest that our moral concern ought to be extended to other natural 
entities they classify 'as individuals', who, they believe, possess interests and a well-being of their own. All these individuals - human, animal and natural - would form the 'community of life' that is both the object and the beneficiary of preservation.

I think it is misguided to include individual natural entities within the moral community. This would be in tension with the grounds for Treves et al.'s individualism and their rejection of moral holism. They claim that individuals matter because they are selves. But it is possible for an entity to be an individual without being a self. For instance, we have criteria that allow us to distinguish between individual molecules, diamonds, asteroids, bicycles and cars, but none of these individual entities is a 'self' except if it is conscious: or, in Nagel's (1974) famous words, 'if there is something that it is like to be' that entity.

Furthermore, only conscious entities can be sentient, i.e., have the capacity for feeling states with positive and negative valences, such as pleasure and suffering. Being sentient is necessary for having interests in attaining the one and avoiding the other - for having a wellbeing which can be increased or reduced by the actions of other sentient beings or by natural events. Sentient beings are the only kinds of individuals who have moral claims and to whom we can owe moral obligations.

It must be further noted that, as far as we know, not all individual natural entities are sentient. Not even all individual organisms are. We have convincing evidence for the sentience of all vertebrate animals, as well as some invertebrates like octopuses (Low et al. 2012; Mather 2019). We have strong but inconclusive evidence for the sentience of other invertebrate taxa, like honeybees or ants (Klein \& Barron 2016). We have scant physiological and behavioral evidence, or none at all, for the sentience of jellyfishes, plants and unicellular organisms (Waldhorn 2019).

Thus, we must distinguish between insentient nature and the community of sentient beings. It is for the benefit of future generations of human and nonhuman sentient individuals that other organisms, ecosystems and the planet must be preserved.

Compassionate preservation requires us to intervene in nature. A second problem in Treves et al.'s account of the ethics of preservation is that it seems to assume that nature does a good job of promoting the interests of nonhuman sentients. On this assumption, the main issue that an ethics of preservation should address is how to balance competing human and nonhuman interests in the planet's resources in a non-anthropocentric way. Past human interference in the natural environment has undeniably been harmful for many nonhuman animals, as well as for other humans. So, in this sense, Treves et al.'s proposal is a step in the right direction. If, as the authors suggest, we should see nonhuman well-being 'as a matter of justice as well as of compassion', harmful interventions in nature must be regarded as morally impermissible.

Nature itself, however, is likely to be harmful overall for wild nonhuman animals, who constitute more than $99 \%$ of all sentient beings (Tomasik 2009). Suffering probably predominates in their lives due to natural events. These include diseases, parasites, starvation, thirst, extreme weather conditions and attacks by other animals (Faria 2016; Horta 2010; Ng 1995; Tomasik 2015). Nature is a moral catastrophe. Suppose we had the risk-free means and competence to make nonhuman animals more resistant to illness, more efficient in processing nutrients and water, as well as the means to control their populations in an ethical way. Suppose, in other words, that we could successfully redesign nature and living organisms so as to ensure that as many sentient beings as possible had good lives. Would we not be morally required to do so? 
The ethical question Treves et al. pose is: what kind of nature do we want to preserve for future generations of sentient human and nonhuman individuals? I believe that when we observe the facts, it becomes clear that we should not try to preserve nature as it would be were it not for human intervention. Based on the compassionate preservation ethics the authors advocate, if nature, as it is, is harmful overall for sentient beings, we should try to improve it, inasmuch as we can.

\section{References}

Bergstrom, B. J. (2019). Just reductionism: In defense of holistic conservation. Animal Sentience 27(8).

Faria, C. (2016). Animal Ethics Goes Wild: The Problem of Wild Animal Suffering and Intervention in Nature, PhD Dissertation. Barcelona: Universitat Pompeu Fabra.

Horta, O. (2010). Debunking the idyllic view of natural processes: Population dynamics and suffering in the wild. Télos, 17, 73-88.

Klein, C. and Barron, A. B. (2016). Insects have the capacity for subjective experience. Animal Sentience 9(1).

Low, P., Panksepp, J., Reiss, D., Edelman, D., Van Swinderen, B. and Kock, C. (2012). The Cambridge Declaration on Consciousness.

Mather, J. (2019). What is in an octopus's mind? Animal Sentience 26(1).

Nagel, T. (1974). What is it like to be a bat? The Philosophical Review, 83 (4): 435-450.

$\mathrm{Ng}, \mathrm{Y}$. K. (1995). Towards welfare biology: Evolutionary economics of animal consciousness and suffering. Biology and Philosophy, 10, 255-285.

Tomasik, B. (2009). How many wild animals are there? Essays on Reducing Suffering.

Tomasik, B. (2015). The importance of wild-animal suffering. Relations: Beyond Anthropocentrism, 3 (1): 133-152.

Treves, A., Santiago-Avila, F. and Lynn, W. S. (2019). Just preservation. Animal Sentience 27(1). Waldhorn, D. R. (2019). Invertebrate Sentience: Summary of Findings, Part 2. Rethink Priorities. Washington, H. (2019). Justice for nature. Animal Sentience 27(2). 


\title{
Call for Papers
}

\author{
Special Issue of the Lournal of Consciousness Studies \\ Plant Sentience: Theoretical and Empirical Issues
}

Guest Editors: Vicente Raja (Rotman Institute of Philosophy, Western University)

Miguel Segundo-Ortin (School of Liberal Arts, University of Wollongong)

In this special issue, we address the issue of plant sentience/consciousness from different disciplines that combine both theoretical and empirical perspectives. Some of the questions to be addressed in the special issue include the following:

- Plants exhibit interesting behaviors; does this entail that they are conscious to some extent?

- What are the requirements for a living organism to be conscious? Do plants meet these requirements?

- What does the possibility of plant sentience/consciousness entail for the study of the evolution of consciousness?

- Is it just a categorical mistake to attribute consciousness to plants?

- Can we talk about different levels or degrees of consciousness?

\section{How to submit?}

Deadline: June 1 $\mathbf{1}^{\text {st }}, \mathbf{2 0 2 0}$

Please submit your papers (max. 9000 words including footnotes, references, abstract, etc.) to vgalian@uwo.ca with subject "Paper Special Issue JCS".

For more information, including bibliography and more detailed descriptions of the topics and questions to be addressed in the papers submitted to the special issue, please contact the guest editors at vgalian@uwo.ca (Vicente) or mso693@uowmail.edu.au (Miguel). 